\title{
Determinantes sócio-históricos do cuidado na Estratégia Saúde da Família: a perspectiva de usuários da área rural'
}

Socio-historical determinants of care in the Family Health Strategy: a user perspective in the rural area

\author{
Edward Meirelles de Oliveira \\ Universidade de São Paulo. Faculdade de Filosofia, Ciências \\ e Letras de Ribeirão Preto. Departamento de Psicologia. \\ Ribeirão Preto, SP, Brasil. \\ E-mail: edmeirelles20ı0@gmail.com \\ Elisangela Aparecida Felipe \\ Empresa Brasileira de Serviços Hospitalares. Universidade Federal \\ do Triângulo Mineiro. Uberaba, MG, Brasil. \\ E-mail: elis.felipeळbol.com \\ Haroldo da Silva Santana \\ Universidade de São Paulo. Faculdade de Medicina de Ribeirão \\ Preto. Departamento de Clínica Médica. Ribeirão Preto, SP, Brasil. \\ E-mail: haroldo_santanazळhotmail.com

\section{Ivonete Helena Rocha} \\ Empresa Brasileira de Serviços Hospitalares. Universidade Federal \\ do Triângulo Mineiro. Uberaba, MG, Brasil. \\ E-mail: ivonetehrochaœhotmail.com

\section{Patricia Magnabosco} \\ Universidade de São Paulo. Escola de Enfermagem de Ribeirão \\ Preto. Departamento de Enfermagem Geral e Especializada. \\ Ribeirão Preto, SP, Brasil. \\ E-mail: patimagnabosco®usp.br

\section{Marco Antonio de Castro Figueiredo} \\ Universidade de São Paulo. Faculdade de Filosofia, Ciências \\ e Letras de Ribeirão Preto. Departamento de Psicologia. \\ Ribeirão Preto, SP, Brasil. \\ E-mail: marcoacfळusp.br
}

\section{Correspondência}

Edward Meirelles de Oliveira

Rua Silvio Crema, 414, Bairro de Lourdes.

Sacramento, MG, Brasil. CEP 38190-000.

\section{Resumo}

O presente estudo teve por objetivo identificar os determinantes sócio-históricos atribuídos pelos usuários às vivências de cuidado na Estratégia Saúde da Família (ESF) na área rural do município de Sacramento/MG. Trata-se de um estudo exploratório com abordagem qualitativa, utilizando para a coleta de dados a técnica de grupos focais e para a interpretação dos resultados, a análise de conteúdo. Foram constituídos três grupos com representantes das famílias de três, dentre seis, povoados rurais, totalizando 36 sujeitos, doze em cada grupo, residentes na área rural e usuários da ESF há pelo menos dois anos, escolhidos com base em fichas de cadastro das famílias na ESF estudada. Sob a perspectiva do materialismo histórico, a análise de conteúdo dos grupos foi concentrada em quatro categorias: disponibilidade; acesso a recursos; movimento social e condições materiais. Os resultados demonstraram satisfação dos usuários em relação à disponibilidade da equipe para a atenção, e o tato nas relações; engajamento na manutenção das condições de saúde e atuação na dimensão sócio-histórica do processo saúde/doença com objetivo de melhorar as condições de vida e trabalho. Houve insatisfação em relação ao aspecto organizacional, remetendo a tudo que ainda está insuficiente, precário ou inexistente nas comunidades. Observou-se na ação da equipe o desenvolvimento de capacidades junto à comunidade que garantiam seus direitos sociais e sua politização. Conclui-se que o enfrentamento do processo saúde/doença pela comunidade e equipe da ESF envolve outros elementos, além do conhecimento

1 Artigo decorrente da dissertação de mestrado do primeiro autor, a qual teve como orientador o Prof. Dr. Marco Antonio de Castro Figueiredo. 
técnico-científico, que determinam a simetria do vínculo profissional/usuário viabilizando a produção conjunta de saúde na comunidade.

Palavras-chave: Estratégia Saúde da Família; Avaliação em Saúde; Pesquisa Qualitativa; População Rural.

\section{Abstract}

This study aimed to identify socio-historical determinants assigned by users to their experience of care in the Family Health Strategy (FHS) in the rural area of the municipality of Sacramento (Southeastern Brazil). This exploratory study with a qualitative approach used the focus group technique to collect data and content analysis to interpret the results. Three groups were formed with representatives from three out of six rural areas, totaling 36 subjects, twelve in each group. They lived in the rural area, had been FHS users for at least two years, and were chosen based on enrollment records of families in the FHS under study. From the perspective of historical materialism, the content analysis of the groups concentrated on four categories: availability, access to resources, social movement and material conditions. The results showed user satisfaction regarding the team's availability to provide care and tact in relationships, engagement in maintaining the health conditions, and action in the sociohistorical dimension of the health/disease process in order to improve life and work conditions. There was dissatisfaction with the organizational aspect, referring to everything that is still insufficient, poor or non-existent in communities. We observed, in the team's actions, the development of capacities in the community that ensured their social rights and politicization. We conclude that the confrontation of the health/disease process by the community and by the FHS team involves other elements, in addition to technical and scientific knowledge, which determine the symmetry of the professional/user bond, enabling joint production of health in the community.

Keywords: Family Health Strategy; Health Evaluation; Qualitative Research; Rural Population.

\section{Introdução}

Diversos autores (Ayres, 2004; Tesser, 2006; Junges et al., 2011) têm verificado que, ao longo da história, o trabalho na atenção em saúde é determinado pelo modelo biomédico, centrado na cura de doenças diagnosticadas exclusivamente por parâmetros biológicos e baseado na relação vertical médicopaciente, em que os determinantes psicossociais são considerados competências de outras especialidades. Este modelo emblemático é hegemônico pela valorização excessiva da formação técnica especializada, medicalização e prevalência da tecnologia.

Atualmente, no Brasil, a Estratégia Saúde da Família (ESF) é o produto de uma política pública com objetivo de mudar esse modelo de assistência (Brasil, 1998). Propõe uma prática assistencial em equipe - centrada nas necessidades da população, considerando-a como partícipe do processo de produção de ações em saúde - suportada por um conhecimento originado na participação social (Crevelim; Peduzzi, 2005). Focada na família, a ESF possibilita às equipes uma compreensão ampliada do processo saúde/doença e da necessidade de intervenções que vão além de práticas curativas (Brasil, 1998).

Desde sua implantação, em 1994, a ESF vem buscando a garantia do acesso equânime à saúde, tomando como princípios básicos a integralidade, a hierarquização, a territorialização, a equipe multiprofissional e o caráter substitutivo do modelo atual de assistência à saúde (Brasil, 2005).

Na prática, a tradução destes princípios no âmbito da saúde tem sido amplamente discutida, principalmente quanto ao caráter substitutivo do modelo atual de assistência (Franco; Merhy, 20o6; Sousa; Hamann, 2009; Silva; Garnelo; Giovanela, 2010), o que pressupõe a necessidade de realizar atividades de avaliação da ESF (Lentsck; Kluthcovsky; Kluthcovsky, 2010; Tanaka, 2011), especialmente frente uma série de portarias publicadas recentemente e que afetam de forma significativa a Atenção Primária à Saúde (APS) no país, seja consolidando a Política Nacional de Atenção Básica - PNAB (Brasil, 2011a) ou instituindo programas como o Programa de Valorização do Profissional da Atenção Básica - PROVAB (Brasil, 2011b), o Programa Nacional de Melhoria do Acesso e da Qualidade 
da Atenção Básica - PMAQ-AB (Brasil, 2011c) e o Programa Mais Médicos (Brasil, 2013).

No Brasil, desde a década de 1990 muitas iniciativas com foco na avaliação da ESF vêm sendo desenvolvidas, mas avaliações sob a perspectiva dos usuários ainda são escassas (Brandão; Giovanella; Campos, 2013).

Segundo Prévost et al. (1998), o interesse pela avaliação da satisfação dos usuários teve início nos primeiros anos da década de 1970. Para Pascoe (1983), a avaliação se baseia em padrões subjetivos, implicando percepções psicológicas de ordem cognitiva e afetiva, em um processo comparativo entre a experiência vivida no enfrentamento das doenças e os critérios subjetivos dos usuários. Para Ware et al. (1983), o índice de satisfação dos usuários é uma avaliação pessoal dos serviços de saúde e de seus prestadores de serviços. Prévost et al. (1998) destacam que abordar a satisfação dos usuários implica trazer à tona julgamentos sobre características dos serviços que podem gerar mudanças e contribuir para melhorias na situação sanitária da população.

Para muitos autores (Trad et al., 2002; Crevelim; Peduzzi, 2005; Franco; Merhy, 2006; Uchoa et al., 2011), o usuário deve ocupar uma posição ativa na dinâmica do cuidado e dos processos decisórios das questões de saúde, o que enfatiza a necessidade de seu protagonismo também nos processos avaliativos do cuidado e dos serviços prestados.

De acordo com Santos, Uchimura e Lang (2005), a avaliação dos serviços de saúde pode assumir enfoques variados, sendo considerada pela maioria dos autores, no âmbito técnico/racionalizador, como prioridade para o aumento da efetividade e da eficácia para a alocação adequada de recursos na atenção, tomando por base critérios resultantes da “apropriação da racionalidade científica, na qual o conhecimento biológico se superpõe a qualquer discussão e descoberta dos significantes socioculturais" (Nuto; Nations, 1999 apud Santos; Uchimura; Lang, 2005, p. 693).

Segundo Deslandes (1997), ao longo dos últimos anos, a avaliação dos serviços de saúde deixou de ser um processo exclusivamente técnico, ou seja, conforme Uchimura e Bosi (2002), já se admite a subjetividade inerente a qualquer avaliação, seja ela de um fato cotidiano, de serviços, estratégia ou programa em especial.

Para os serviços de saúde, as avaliações, sobretudo num enfoque que privilegie a experiência do usuário no sistema de saúde, contemplando sua subjetividade, podem trazer informações relevantes sobre como a assistência é percebida por ele; trazendo à tona conhecimento que possa "subsidiar a reorientação da formação para a capacitação do profissional de saúde no sentido de poder sistematizar e aproveitar a aprendizagem informal, acumulada pela experiência no trato com o paciente" (Figueiredo, 200o, p. 86).

Alguns estudos apresentam a visão do usuário de grandes cidades acerca do cuidado prestado pela ESF (Trad et al., 2002; Aguiar; Moura, 2004; Santos; Uchimura; Lang, 2005; Oliveira; Borges, 2008; Souza et al., 2008; Mishima et al., 2010; Serapioni; Silva, 2011; Brandão; Giovanella; Campos, 2013; Chagas; Vasconcelos, 2013). Outros, em número bem menor, apresentam a visão dos usuários de áreas rurais de pequenos municípios (Cotta et al., 2005; Gomes et al., 2009; Uchoa et al., 2011), tornando necessária a realização de mais estudos com este recorte.

Desta forma, identificar os determinantes sócio-históricos atribuídos pelos usuários às vivências de cuidado na Estratégia Saúde da Família na área rural de um pequeno município do estado de Minas Gerais foi o objeto deste estudo, que pode contribuir para a concepção de estratégias que venham ampliar o contexto de assistência à saúde e cuidado às pessoas.

\section{Método}

O estudo foi realizado na área rural do município de Sacramento, cidade localizada na região do Alto Paranaíba, estado de Minas Gerais. Conforme dados do IBGE de 2010, ${ }^{2}$ o município possui uma população de 23.896 habitantes, sendo 19.275 (8o,66\%) concentrados na área urbana e 4.621 (19,34\%) na área rural.

De acordo com Devós (2013), dentre as atividades econômicas do município sempre se destacaram as do setor rural, produtor de café, milho, soja, batata, madeira, cana-de-açúcar e leite. 0 setor agropecuá-

2 IBGE. Censo Demográfico 2010. Disponível em: 〈http://www.censo2010.ibge.gov.br>. Acesso em: 27 jun. 2014. 
rio contribuiu, em 2011, com 35,84\% das riquezas produzidas no município e, em 2012, com 39,14\%.

O município conta com seis equipes da ESF, distribuídas em seis microáreas, uma delas com atuação exclusivamente rural, que atende aproximadamente 700 famílias. Cada microárea representa um dos povoados localizados em áreas distantes da cidade e entre si. Seus núcleos não detêm mais que $20 \%$ das famílias, que em sua maioria se distribuem entre fazendas também distantes umas das outras. A microárea mais próxima dista $42 \mathrm{~km}$ da cidade, a mais distante, $82 \mathrm{~km}$. Alguns locais de atendimento da equipe ficam a $90 \mathrm{~km}$. As estradas são todas de terra. 0 deslocamento é diário, o tempo varia de 50 minutos a 2 horas, fazendo com que as distâncias e as condições de tráfego e locomoção se tornem um dos principais desafios para a interação com as comunidades rurais, historicamente relegadas a segundo plano (Santana, 2008; Oliveira, 2009).

0 presente estudo trata-se de uma pesquisa exploratória com abordagem qualitativa realizada junto a três, dentre seis, povoados rurais atendidos pela Estratégia Saúde da Família rural do município de Sacramento/MG. Em virtude da acessibilidade, os povoados escolhidos foram os mais próximos da cidade (Jaguarinha - $42 \mathrm{~km}$; Bananal - 54 km e Quenta-Sol - 56 km). 0 trabalho de campo foi desenvolvido entre julho e dezembro de 2007. Apesar dos sete anos decorridos da coleta, os dados demonstram-se atuais, sobretudo pela pouca ou nenhuma mudança na realidade de vida das famílias/comunidades, tampouco na "oferta" dos serviços de saúde neste período.

A coleta de dados foi realizada com base na técnica de grupo focal, entrevista que tem por objetivo extrair dados descritivos de um subgrupo populacional, com base na interação, durante discussões sobre determinados tópicos de interesse comum. Os trabalhos grupais foram realizados com a participação de um coordenador, além de um moderador que desempenhava a função de criar elementos de facilitação e regulação da discussão, registrando aspectos não verbais e a dinâmica de interação dos participantes (Pope; Mays, 2005).

A decisão sobre a inclusão dos sujeitos nos grupos focais foi baseada em fichas de cadastro das famílias na ESF rural estudada. Após a escolha da família e esclarecimentos sobre o estudo, era solicitado que esta realizasse uma eleição, ou indicação por consenso, de uma pessoa da residência em questão com motivação e disponibilidade para participar do estudo e que atendesse aos critérios de inclusão: ter 18 anos ou mais, ser residente na área rural e usuário da Estratégia Saúde da Família há pelo menos dois anos. Foram constituídos três grupos, cada um com 12 usuários, um em cada povoado. Os participantes tinham idades variadas (de 24 a 73 anos), prevalecendo o sexo feminino.

Para a coleta de dados, foram realizados seis encontros, dois com cada grupo, cada um com duração aproximada de uma hora e trinta minutos. 0 tópico-guia teve como foco a opinião dos usuários sobre o cuidado prestado pela equipe rural da ESF, as discussões foram gravadas e transcritas na íntegra. Leituras reiteradas das transcrições permitiram, via análise de conteúdo (Minayo, 200o), identificar alguns núcleos temáticos sobre o cuidado em saúde realizado pela equipe da Estratégia Saúde da Família rural de Sacramento.

Sob tal perspectiva, o referencial do materialismo histórico leva a subordinação do trabalho à lógica do modo de produção vigente, e sua determinação no processo de reificação instalado no trabalho em saúde.

Este estudo deriva da dissertação de mestrado intitulada "Processos de apropriação da prática na construção do cuidado em saúde, sob a perspectiva de usuários do Programa de Saúde da Família Rural de Sacramento/MG", foi submetido e aprovado pelo Comitê de Ética em Pesquisa da Faculdade de Filosofia, Ciências e Letras de Ribeirão Preto (USP); cumprindo todas as normatizações da Comissão Nacional de Ética em Pesquisa (CONEP), presentes na resolução n. 196/96 do Conselho Nacional de Saúde, que dispõe sobre as diretrizes e normas regulamentadoras de pesquisas envolvendo seres humanos.

\section{Resultados e discussão}

O cuidado realizado pela equipe da ESF rural de Sacramento aponta para uma configuração pouco comum no trabalho em saúde: tomando por base a participação da comunidade, inclui a lógica da determinação sócio-histórica no processo saúde/ 
doença, viabilizando aos profissionais de saúde uma análise contextual de suas práticas.

A síntese das crenças e representações obtidas com base em análise de conteúdo dos grupos focais permitiu identificar quatro categorias temáticas: disponibilidade; acesso a recursos; movimento social e condições materiais.

\section{Disponibilidade}

Esta categoria permitiu identificar elementos sobre a relação entre a equipe da ESF rural e a comunidade, viabilizando a síntese de processos conjugados. A avaliação da equipe foi marcada pela concepção do rapport (relação de compreensão, de solidariedade, de respeito mútuo, de atitude empática), enquanto facilitador do vínculo com a comunidade e pela disponibilidade para a atenção e tato nas relações.

Com essa equipe a gente se sente num consultório particular, sem pressa! Tem aquele tempo para conversar sobre os problemas familiares, os problemas de saúde. (Grupo Focal 2)

Essa equipe não pensa somente no atendimento da saúde corporal, pensa no bem-estar físico, social e mental da turma em geral. (Grupo Focal 3)

Ainda, com relação à avaliação da equipe, foram identificadas representações que valorizaram presteza e pronto atendimento na resolutividade das demandas como elementos que facilitam o acesso aos recursos. A equidade foi identificada como critério que garante o acesso às práticas de saúde, sem discriminação, e como compensação das dificuldades enfrentadas pelas comunidades rurais, determinadas pelas condições de acesso aos serviços de saúde.

A equipe médica que atende aqui é muito boa, [...] o doutor é um espetáculo de bom, atende com muita educação, a enfermeira também, a Dona M (ACS) do postinho nem se fala de tão boa que é! Até de noite, meia-noite, a gente vem aqui e ela atende. (Grupo Focal 1)

Nós que moramos aqui, distante da cidade, tínhamos que ter a preferência e sermos atendidos mais rápido. Para o povo da cidade tudo é mais fácil. (Grupo Focal 2)
Segundo relatos, foi possível perceber a disponibilidade da equipe para com as necessidades dos usuários, mesmo fora da área de abrangência de sua microárea, realizando acolhimento e criação de vínculo independente dos limites burocráticos. Essa ação reforça a teoria do rapport, presteza e pronto atendimento, enquanto componentes do processo de acolhimento, da facilitação na criação de vínculo e do processo terapêutico.

Estando com o jornal que a própria equipe fornece, dá pra gente ver que hoje ela está aqui, amanhã está em tal lugar e em qualquer lugar que você procurar atendimento eles atendem a gente com a máxima atenção. (Grupo Focal 3)

Antes a gente não podia sair da nossa comunidade pra ser atendido pelo médico lá nas outras comunidades. Agora pode! A gente sai daqui se estiver doente vai à comunidade $A$ ou $B$, que é atendido. (Grupo Focal 2)

Tais depoimentos permitiram observar a disponibilidade da equipe para reduzir os déficits assistenciais, derivados da organização diferençada do processo de trabalho na área rural, no qual a equipe semanalmente se deslocava para várias microáreas, gerando vazios assistenciais com periodicidade regulada pelo próprio prestador de serviços. Vazios estes também observados no estudo de Uchoa et al. (2011).

Em conformidade com o trabalho de Uchoa et al. (2011), a inexistência das unidades de Saúde em algumas localidades de atendimento, e a grande distância dessas localidades até a unidade mais próxima, fazia com que a equipe atendesse em locais impróprios, o que foi reconhecido pelos usuários:

Eu queria agradecer à equipe médica, que enfrenta várias dificuldades nas estradas, poeira, barro, buracos, falta de banheiro na capela onde é feito o atendimento e várias outras. (Grupo Focal 3)

A análise aponta, como em outros trabalhos (Trad et al., 2002; Aguiar; Moura, 2004; Cotta et al., 2005; Souza et al., 2008; Serapioni; Silva, 2011; Uchoa et al., 2011), que a satisfação dos usuários está associada a atributos como respeito, consideração, escuta, compreensão, facilidade de acesso aos profissionais, ampliação das ações de saúde e melhorias do nível de 
informação sobre o processo saúde/doença, quando comparadas à assistência prestada pelas equipes anteriores.

O outro médico que tinha aqui não atendia se fosse de outra comunidade. Se ele tivesse atendendo aqui e viesse uma pessoa de outra comunidade, ele não atendia. (Grupo Focal 2)

Não obstante, sob a perspectiva dos usuários, disponibilidade representa satisfação com o engajamento contínuo dos profissionais da equipe no processo de construção do cuidado para o enfrentamento do processo saúde/doença. Tal concepção está além da visão de acesso enquanto disponibilidade/oferta de consumo, garantido pela distribuição planejada de recursos em um sistema de saúde hierarquizado e organizado com bases no princípio da referência/ contrarreferência. Segundo Serapioni e Silva (2011), o usuário procura o atendimento como forma de ser escutado e de expressar seus problemas, que nem sempre são referentes ao próprio estado de saúde.

O médico está ocupado com esse lixão aqui. Eles [a equipe da ESF] estão procurando saber o que fazer com esse lixão. Eles também estão sempre empenhados em benefícios para a comunidade, tais como a água, rede de esgoto, energia rural e outros mais. Eles estão sempre procurando melhorias aqui para a comunidade. (Grupo Focal 3)

Contrárias às percepções identificadas por Mandú et al. (2008) e Uchoa et al. (2011), em que as visitas eram centradas especificamente em ações clínico-educativas, no presente estudo, as visitas foram destaque nos relatos dos grupos, sendo explícito o objetivo de atuar na dimensão social do processo saúde/doença, com o propósito de melhorias das condições de vida e trabalho.

Foram muito boas essas visitas do doutor junto com a assistente social, porque ela pode ver como são as coisas em cada família, a necessidade de cada família. (Grupo Focal 2)

Nas visitas, tudo que você acha importante, você expõe pra eles [...], está servindo de orientação pra eles, pra eles estarem ajudado as pessoas da comunidade. (Grupo Focal 1)
Outro elemento impactante aos usuários era receber a visita do médico, que realizava os trajetos a pé, estreitando o vínculo com a comunidade. Para Chacra (2005), o vínculo é a ligação efetiva entre dois sujeitos, que na maioria das vezes estão colocados um diante do outro em posições assimétricas e que precisam estabelecer, entre si, uma comunicação eficiente; implica aceitação do outro, responsabilidade e respeito pela autonomia de cada um dos envolvidos.

Andar nessas estradas ruins não é fácil! A pessoa sofre de fazer isso. Igual eles saíram andando, não é para qualquer médico! Essas caminhadas a pé! O dia inteirinho, isso não é fácil! (Grupo Focal 2)

Destaca-se que disponibilidade não é protocolar e não se trata apenas de cortesia ou educação para com o outro, mas consiste na abertura dos serviços para a demanda e responsabilização por grande parte dos problemas de uma coletividade, estando relacionada a uma identidade de origem que, de acordo com Coelho Jr. (2004), significa uma capacidade de compreender os sentimentos e os pensamentos do outro, colocando-se em seu lugar. Para Santana (2008), a identidade entre equipe e comunidade apresenta sua melhor função à medida que deriva de ações produtoras de conhecimento das pessoas e do ambiente em que atua, ou seja, da realidade em que se trabalha, da realidade vivida, um conhecimento muito valorizado pela população rural.

O principal que eles têm é essa atenção, esse atendimento $100 \%$. É porque eles vivem o dia a dia na zona rural, então, eles conhecem os nossos problemas. (Grupo Focal 2)

A ação da equipe da ESF rural era valorizada pelo trabalho desenvolvido e por uma série de melhorias promovidas na vida dos moradores das áreas atendidas. No entanto, a maioria dos usuários não fazia alusão ao termo PSF ou ESF, utilizando: postinho, equipe médica ou equipe dos agentes de saúde. Situação também constatada nos estudos de Trad et al. (2002), Gomes et al. (2009) e Uchoa et al. (2011).

Para a comunidade, não é o nome ou o modo de orientação do projeto ou da estratégia, mas os resultados obtidos, o que reitera a importância da formação e do papel dos profissionais de saúde quanto à 
consolidação da ESF e do Sistema Único de Saúde (SUS), uma vez que são eles quem efetivamente implementam os princípios e diretrizes preconizados.

\section{Acesso a recursos}

Nesta categoria, os relatos apontaram para uma avaliação dos elementos da dimensão organizacional, necessários e complementares à Atenção Primária à Saúde, considerando o acesso à distribuição de medicamentos, agendamento de consultas em serviços de referência e realização de exames clínicos.

Como critérios comuns de avaliação, observaram-se insuficiência, inexistência e demora no atendimento, que levam a implicações negativas como descontinuidade da Atenção Primária e o esgotamento de recursos financeiros dos usuários em função de custos para o acesso aos serviços e de perdas salariais por descontos em jornadas não trabalhadas.

Está faltando remédio, não tem remédio nenhum aqui. Nós estamos precisando de remédio e vir mais vezes por mês aqui, porque desse mês passado para cá vieram só uma vez. Um mês e quinze dias, então se fosse pelo menos de quinze em quinze dias. (Grupo Focal 2)

Acho que a dificuldade que a gente temé quando vai marcar os exames, eles demoram a ser agendados. Para marcarmos os exames na cidade a gente perde o dia de trabalho, perde de novo quando vaifazer os exames e fica gastando. (Grupo Focal 3)

Minayo (2000) destaca que a concepção de doença nas classes trabalhadoras é localizada no corpo e se encontra vinculada à questão da produção. A saúde é uma condição necessária a uma vida ativa, à própria capacidade para o trabalho.

Dentre as várias dimensões da vida humana contempladas nesta noção de condições de vida, destaca-se o cuidado com a saúde sem, no entanto, desconsiderar as contradições das forças produtivas da sociedade que configuram a atual questão social brasileira, que ora limitam, ora potencializam o processo organizativo dos trabalhadores rurais.

Neste contexto, resultados semelhantes aos do estudo de Trad et al. (2002) demonstram que a presença de profissionais na configuração da equipe mínima não supre a demanda por cuidado integral da população, havendo queixas de insuficiência ou inexistência de assistentes sociais, nutricionistas, pediatras, ginecologistas/obstetras e psicólogos.

Algumas casas tinham que ser mais visitadas pela assistente social, por estar mexendo com os benefícios [aposentadorias] e pela nutricionista, para olhar a parte de alimentação. (Grupo Focal 2)

Precisava ter aqui uma ginecologista ou um pediatra para ajudar o doutor, não digo toda vez que ele viesse, mas que fosse pelo menos uma vez por mês. (Grupo Focal 2)

Uma das características fundamentais do trabalho em regiões rurais é estar ancorado na apropriação da terra, enquanto condições de vida, com suas características históricas, na qual a racionalidade técnica não está implantada. Desta maneira, no contexto de luta por melhores condições de vida e trabalho no campo, a ênfase é colocada nas atividades que reduzam o deslocamento ou as dificuldades de acesso aos serviços de saúde e à assistência especializada.

Estamos fazendo uma reunião para pedirmos uma ambulância para morar aqui, são quase $80 \mathrm{~km}$, daqui a Sacramento. Há pouco tempo, uma cobra pegou a mãe e a menina e se não tem um passando com o carro, elas tinham morrido. Não tem socorro! (Grupo Focal 1)

Eu queria que tivesse uma lotação para levar pelo menos as pessoas que precisam de tratamento psicológico e de hidroginástica para a cidade, levar pelo menos três vezes por semana, uma Kombi! (Grupo Focal 3)

Falta coletar exames no dia do atendimento médico e levar para a cidade. (Grupo Focal 2)

De maneira geral, as queixas relativas ao aspecto organizacional remetem ao que ainda está insuficiente, precário ou inexistente nas comunidades. Sem negar melhorias de acesso em relação aos serviços anteriormente oferecidos, tais elementos, como no trabalho de Trad et al. (2002), denunciam um sentimento de desamparo e perplexidade frente à lógica que governa o processo demanda/atenção. 
Precisava melhorar esse negócio de esperar, às vezes a doença não espera! Marca um exame e aí precisa esperar atémais de mês! Tinha que ser mais rápido. (Grupo Focal 2)

A inexistência de unidades de saúde em determinadas localidades, assim como a não permanência diária da equipe, especificamente do médico, e a falta de equipamentos básicos também foram reivindicados, corroborando os achados de Uchoa et al. (2011).

O local do atendimento do médico é uma sala, numa casa. Poderia tá tendo um posto, tá faltando só um posto aqui na comunidade. (Grupo Focal 3)

Precisava ter mais médico para ajudar ele, não pode ser ele sozinho ou ele vir mais vezes por semana né? (Grupo Focal 2)

Precisa trazer mais uma maca, às vezes, a pessoa chega passando mal e tem que ficar sentado na cadeira. Precisava também de um suporte pra pôr soro. (Grupo Focal 2)

\section{Movimento social}

Discutir, neste estudo, a categoria movimento social implica em percorrer o trajeto de compreensão da inclusão da equipe de saúde e dos usuários no que se refere às decisões estabelecidas ao longo do enfrentamento do processo saúde/doença no decorrer da história. Tal processo subentende definir como se criam espaços de participação da comunidade junto aos serviços de saúde e qual o papel da equipe nesse espaço de legitimação do poder popular.

Nesta categoria, foram identificados conteúdos sobre a identidade de perspectivas entre comunidade e equipe da ESF rural, considerando: a) apropriação das práticas em saúde via trabalho coletivo; b) politização, pela comunidade, viabilizando identificação de diferentes contextos de atenção em saúde; c) convívio, com visibilidade para as demandas e necessidades, concebidas como domínio do coletivo formado por profissionais e comunidade, legitimando o trabalho da equipe.

A manutenção das condições de saúde na comunidade é um elemento constitutivo do processo de construção do cuidado, pautado na práxis do trabalho coletivo desenvolvido no cotidiano. Tal processo se revela no relato, evidenciando a apropriação da prática em saúde da comunidade pela equipe.

Eles [a equipe] estão sempre empenhados nos problemas da comunidade que não têm nada a ver com a saúde, igual no caso da energia da zona rural, na reforma das casas. (Grupo Focal 1 )

Para Scopinho (2010), os trabalhadores rurais constroem e partilham sentidos sobre a realidade vivida com a finalidade não apenas de interpretála, mas também de transformá-la, expressando suas identidades sociais e culturais geradas pela integração das suas experiências às práticas cotidianas, refletindo e constituindo reflexos da estrutura social, da ideologia e da cultura que as sustentam.

Para várias pessoas, a moradia está difícil, tem pessoas que estão vivendo em barracões, lugar aberto, em contato com inseto, barbeiro e outros tipos, aqui tem muita cobra na região. (Grupo Focal 3)

Uma nova concepção do processo saúde/doença tem demonstrado que o contexto pode exercer um papel terapêutico importante, assim como serviços de saúde efetivos, dado o sentimento de confiança criado na população. Para Pinheiro (2002), a saúde é o resultado de uma produção social que determina qualidade de vida, entendida como condição de existência no cotidiano, que pressupõe determinado nível de acesso a bens, serviços econômicos e sociais. Assim, a saúde pode ser concebida como a realização de um conjunto de necessidades sociais, que precisam ser resolvidas além da práxis médica. A equipe, como um todo, pode desenvolver capacidades junto à comunidade, garantindo seus direitos sociais e sua politização.

Tinha aquele salário maternidade, benefício que a pessoa tinha direito, eu mesmo não recebi por falta de informação, mas o doutor falou pra todas as mulheres que ganharam neném e todas estão recebendo. (Grupo Focal 1 )

Eu achei interessante, eles levantaram a Associação de Desenvolvimento Rural aqui e não tinha a ver com a saúde, mas eles apoiaram as famílias e a comunidade. (Grupo Focal 3) 
Propor ações em saúde significa, a priori, conhecimento e compreensão, por parte da equipe, sobre a vida em determinada comunidade. Uma alternativa seria transcender a visão e a postura acadêmica, valorizando o discurso e a história das comunidades, incorporando ao conhecimento biológico, as dimensões sociais e culturais. Esta atitude perante a vida da comunidade pode legitimar o trabalho a partir do convívio cotidiano, vivenciado a partir de uma relação de iguais entre comunidade e profissionais.

o que eu achei interessante é que eles quiseram visitar as famílias a pé, não de carro! Eles quiseram ver as dificuldades que cada um tinha de enfrentar pra chegar até o posto de saúde ou até a cidade, a distância da casa. (Grupo Focal 3)

As reuniões realizadas pela equipe com a comunidade constituíram momento imprescindível de cooperação e síntese resultante; discutia-se, com a população em geral, os problemas do cotidiano e a interferência destes no seu estado de saúde, permitindo a inclusão dos usuários no que se refere às decisões sobre os problemas a serem enfrentados. Tais achados se apresentaram contrários aos encontrados por Uchoa et al. (2011), em que não foram observadas iniciativas multidisciplinares e intersetoriais com a finalidade de alavancar os potenciais de enfrentamento das condições adversas, individuais e/ou coletivas.

Uma vez por mês tem a reunião com a população, sempre tem essa reunião. Nessa reunião eles deixam em aberto: as pessoas podem agradecer; fazer reivindicações; falar o que quiser. (Grupo Focal 1)

Nós tivemos também um problema de água, eles trouxeram uma pessoa do SAAE aqui no dia da reunião. (Grupo Focal 3)

$\varepsilon$ É uma reunião onde é chamado todo mundo, onde eles mandam um papelzinho convidando, mas muita gente não vem, às vezes até do próprio arraial. (Grupo Focal 3)

\section{Condições materiais}

Como citado anteriormente, uma das características fundamentais do trabalho em regiões rurais é estar ancorado na apropriação da terra, enquanto con- dição material de vida. Neste contexto, destaca-se a necessidade de entender a saúde na sua relação direta com o campo. Desta forma, foram observados conteúdos sobre a importância dos equipamentos e serviços coletivos de apoio às famílias, como condições de moradia, sistema de telefonia, mobilidade, saneamento, etc., que podem influenciar, de modo decisivo, as condições de vida e a capacidade de permanência das famílias no campo.

Aqui a gente só tem um telefone na comunidade. $\bar{\varepsilon}$ da associação comunitária, o outro é no Desemboque, a vinte e tantos quilômetros. A comunidade é grande e depende muito do telefone. (Grupo Focal 2)

Eu moro em um paiol, é um lugar quase que aberto, até cobra nós já matamos dentro do paiol, vários estão nas mesmas condições que eu, morando em barraco. (Grupo Focal 3)

A gente tá falando sobre saúde, mas estrada também é saúde. Porque se ficar doente aqui, tendo uma estrada em boas condições rapidinho a gente tá no atendimento médico, mas se a estrada estiver péssima, vai acontecer de não chegar a tempo no atendimento. (Grupo Focal 2)

Ainda em relação às condições materiais, foi identificado um conjunto de crenças e representações sobre as dificuldades frente à manutenção das conquistas da comunidade rural, anomia esta dada por falta de organização e consequente depreciação dos espaços e recursos coletivos para promoção da saúde:

Nós estamos precisando de uma reforma no postinho, fazer um muro em volta dele, porque fica gente bagunçando no telefone de noite. (Grupo Focal 1)

Eu queria pedir para colocar relógio de água aqui, tem gente que nem torneira tem, o cano fica aberto dia e noite e se esse poço secar? Nós estamos perdidos! Além disso, a água do córrego tá toda poluída com as lavouras, tá cheia deveneno! (Grupo Focal 3)

Para Meireles (2001), incluir a anomia como fenômeno sociológico torna-se imprescindível em uma reflexão sobre a atenção em saúde atual, por tratar-se de referenciais mínimos e organizadores da sociedade, que resultam da dirupção dos processos 
determinantes da ordem coletiva. Essa ausência de normas, do ponto de vista social, é a baliza que falta ao cidadão para definir os objetivos de sua ação.

A anomia incide sobre o movimento social determinando a inércia e a falta de autonomia da comunidade. Como afirma Fernandes (1996), a anomia teria passado a ocupar o lugar de onde foi desalojada a autonomia. Tal processo potencializa a vulnerabilidade da comunidade frente à exclusão do processo saúde/doença, determinada pela precariedade das condições materiais de vida e trabalho, que incidem sobre o acesso aos recursos de atenção à saúde.

\section{Considerações Finais}

A precariedade das condições de vida e trabalho no meio rural, a inexistência e a dificuldade de acesso aos serviços de saúde e à atenção especializada, bem como a falta de informação, constituem os mais importantes desafios históricos a serem superados na defesa da condição de vida/trabalho e saúde dos moradores da área rural de Sacramento.

Foi observado, mediante a organização "diferençada" de trabalho da equipe, que as comunidades ficam desassistidas em períodos regulados pelo próprio prestador de serviços. A aparência eminentemente técnica do planejamento do trabalho da equipe esconde objetivos políticos de racionalização da escassez de recursos e barateamento da mão de obra do setor da saúde. Atitude semelhante pode ser observada na Política Nacional de Atenção Básica - PNAB (Brasil, 2011a), ao flexibilizar a carga horária dos médicos nas equipes de Saúde da Família que, a partir dessa portaria, podem ser de 20, 30 ou 40 horas semanais.

A flexibilização, incorporada pela PNAB, pode complicar o processo de trabalho das equipes da ESF, diminuindo a permanência do médico na unidade e, consequentemente, prejudicando o vínculo com a família/comunidade e impossibilitando uma atuação sobre os determinantes sócio-históricos do cuidado em saúde. Além disso, não atua no que, particularmente, acreditamos ser mais importante: garantir a desprecarização dos vínculos de trabalho e a instituição de um Plano de Cargos, Carreira e Salários adequado; assim protegendo a ESF da falta de sustentabilidade político-financeira nos diversos municípios brasileiros.
Tais fatos contribuem para a manutenção do modelo hegemônico, delegando aos sujeitos os cuidados sobre si mesmos, o que só reforça a tendência de redução da responsabilidade do Estado na solução dos problemas sociais.

Não obstante, foi devido à organização "diferenciada" da equipe, com disponibilidade às necessidades da comunidade, que as consequências dos vazios assistenciais foram minimizadas, destacando-se, conforme depoimentos, um elevado grau de satisfação dos usuários, referente à dimensão relacional com a equipe e seus profissionais. Nesse sentido, observa-se que, no cuidado em saúde, não há como separar condições de vida/trabalho e saúde.

É fundamental compreender o acesso e a integralidade dos serviços enquanto direito individual e coletivo, baseado em um conhecimento ampliado advindo da práxis, explicitando a construção do cuidado em saúde dentro de uma perspectiva de múltiplos enfoques, com vistas à garantia da resolutividade.

Quanto à participação popular, há que se trabalhar sob a perspectiva da conquista da autonomia dos sujeitos, a quem se deve dar condições de decidir entre as alternativas possíveis. Não há que se restringir a participação popular apenas ao instituído: os conselhos municipais e conferências de saúde. A participação popular se estende ao cotidiano, à politização e democratização da gestão em saúde, segundo as necessidades do enfrentamento do processo saúde/doença.

Como afirma Scopinho (2010), a saúde deveria ser o resultado de políticas econômicas e sociais voltadas para a equidade, que tanto possam garantir o acesso dos trabalhadores aos meios de produção, aos direitos sociais e aos bens de consumo coletivos quanto cultivar valores de justiça, equidade e organização política.

Pode-se inferir que as tentativas para solucionar os problemas e concretizar os princípios e diretrizes preconizados pela ESF esbarram em obstáculos relacionados à falta de condições materiais para viabilizar a vida social (moradia, estradas, telefonia, água, energia elétrica, transporte, assistência à saúde); bem como na dificuldade para superar uma atitude reificada de submissão e dependência, que individualiza e naturaliza os agravos à saúde. 
A concepção de atividades que possibilitem, na relação entre usuários e equipe, o enfoque dos significados sócio-históricos do processo saúde/ doença permite que as expectativas iniciais de diagnóstico e intervenções puramente biológicas sejam modificadas ao longo do processo de atendimento, incorporando a função terapêutica de ampliar a compreensão da experiência do cuidado em saúde para além dos limites da objetivação científica (Rozemberg; Minayo, 2001).

As atividades reificadas em saúde podem ser enfrentadas com investimentos na formação de profissionais e novos pesquisadores na área, com uma abordagem multivariada advinda da relação com a comunidade, onde a intencionalidade permite uma resposta às suas necessidades determinada pela síntese da ciência com o conhecimento informal, possibilitando uma construção conjunta de conhecimento em vista de um cuidado em saúde integral.

\section{Referências}

AGUIAR, A. C. S.; MOURA, E. R. F. Percepção do usuário sobre a atuação da Equipe de Saúde da Família de um distrito de Caucaia/CE. Revista Brasileira em Promoção da Saúde, Fortaleza, v. 17, n. 4, p. 163-169, 2004.

AYRES, J. R. C. M. O cuidado, os modos de ser (do) humano e as práticas de saúde. Saúde e Sociedade, São Paulo, v. 13, n. 3, p. 16-29, 2004.

BRANDÃO, A. L. R. B. S.; GIOVANELLA, L.; CAMPOS, C. E. A. Avaliação da atenção básica pela perspectiva dos usuários: adaptação do instrumento EUROPEP para grandes centros urbanos brasileiros. Ciência \& Saúde Coletiva, Rio de Janeiro, v. 18, n. 1, p. 103-114, 2013.

BRASIL. Ministério da Saúde. Secretaria de Assistência à Saúde. Coordenação de Saúde da Comunidade. Saúde da Família: uma estratégia para a reorientação do modelo assistencial. Brasília, DF, 1998.

BRASIL. Ministério da Saúde. Fundação Oswaldo Cruz. Saúde da Família: avaliação da implementação em dez grandes centros urbanos: síntese dos principais resultados. Brasília, DF, 2005. (Série C. Projetos, Programas e Relatórios).
BRASIL. Ministério da Saúde. Gabinete do Ministro. Portaria $n^{0} 2.488$, de 21 de outubro de 2011. Aprova a Política Nacional de Atenção Básica, estabelecendo a revisão de diretrizes e normas para a organização da Atenção Básica, para a Estratégia Saúde da Família (ESF) e o Programa de Agentes Comunitários de Saúde (PACS). Diário Oficial da União, Brasília, DF, 24 out. 2011a. Seção 1, p. 48.

BRASIL. Ministério da Saúde. Gabinete do Ministro. Portaria Interministerial MS/MEC $\mathrm{n}^{0}$ 2.087, de $1^{\circ}$ de setembro de 2011. Institui o Programa de Valorização do Profissional da Atenção Básica. Diário Oficial da União, Brasília, DF, 2 set. 2011b. Disponível em: <http:// bvsms.saude.gov.br/bvs/saudelegis/gm/2011/ pri2087_01_09_2011.html>. Acesso em: 5 jul. 2014.

BRASIL. Ministério da Saúde. Gabinete do Ministro. Portaria ${ }^{0} 1.654$, de 19 de julho de 2011. Institui, no âmbito do Sistema Único de Saúde, o Programa Nacional de Melhoria do Acesso e da Qualidade da Atenção Básica (PMAQ-AB) e o Incentivo Financeiro do PMAQ-AB, denominado Componente de Qualidade do Piso de Atenção Básica Variável - PAB Variável. Diário Oficial da União, Brasília, DF, 20 jul. 2011c. Seção 1, p. 79.

BRASIL. Lei no 12.871, de 22 de outubro de 2013. Institui o Programa Mais Médicos, altera as Leis $n^{0} 8.745$, de 9 de dezembro de 1993 , e n ${ }^{0} 6.932$, de 7 de julho de 1981, e dá outras providências. Diário Oficial da União, Brasília, DF, 23 out. 2013. Seção 1, p. 1.

CHACRA, F. C. Metodologia centrada na primeira pessoa na experiência do Vínculo. In: BARROS, N. F.; CECATTI, J. G.; TURATO, E. R. (Org.). Pesquisa qualitativa em saúde: múltiplos olhares. Campinas: Komedi: Unicamp, 2005, p. 185-192.

CHAGAS, H. M. A.; VASCONCELLOS, M. P. C. Quando a porta de entrada não resolve: análise das unidades de saúde da família no município de Rio Branco, Acre. Saúde e Sociedade, São Paulo, v. 22, n. 2, p. 377-388, 2013.

COELHO JR, N. E. Ferenczi e a experiência da einfühlung. Ágora, Rio de Janeiro, v. 7, n. 1, p 73-85, 2004 . 
COTTA, R. M. M et al. A satisfação dos usuários do Programa de Saúde da Família: avaliando o cuidado em saúde. Scientia Medica, Porto Alegre, v. 15 , n. 4, p. 227-234, 2005.

CREVELIM, M. A.; PEDUZZI, M. Participação da comunidade na equipe de saúde da família: é possível estabelecer um projeto comum entre trabalhadores e usuários? Ciência \& Saúde Coletiva, Rio de Janeiro, v. 10, n. 2, p. 323-331, 2005.

DESLANDES, S. F. Concepções em pesquisa social: articulações com o campo da avaliação em serviços de saúde. Cadernos de Saúde Pública, Rio de Janeiro, v. 13, n. 1, p. 103-107, 1997.

DEVÓS, L. Fontes das riquezas produzidas em Sacramento: relatório técnico. Sacramento: Prefeitura Municipal de Sacramento, 2013.

FERNANDES, H. R. Um século à espera de regras. Tempo Social: Revista de Sociologia da USP, São Paulo, v. 8, n. 1, p. 71-83, 1996.

FIGUEIREDO, M. A. C. Aids, ciência e sociedade. In: BOARINI, M. L. (Org.). Desafios na atenção à saúde mental. Maringá: EDUEM, 2000. p. 79-92.

FRANCO, T. B.; MERHY, E. E. Programa de Saúde da Família (PSF): contradições de um programa destinado à mudança do modelo tecnoassistencial. In: MERHY, E. E. et al. (Org.). O trabalho em saúde: olhando e experienciando o SUS no cotidiano. São Paulo: Hucitec, 2006. p. 53-124.

GOMES, K. O. et al. Avaliação do impacto do Programa Saúde da Família no perfil epidemiológico da população rural de Airões, município de Paula Cândido (MG), 19922003. Ciência \& Saúde Coletiva, Rio de Janeiro, v. 14, p. 1473-1482, 2009. Suplemento 1.

JUNGES, J. R. et al. Saberes populares e cientificismo na estratégia saúde da família: complementares ou excludentes? Ciência \& Saúde Coletiva, Rio de Janeiro, v. 16, n. 11, p. 4327-4335, 2011.

LENTSCK, M. H.; KLUTHCOVSKY, A. C. G. C.; KLUTHCOVSKY, F. A. Avaliação do Programa Saúde da Família: uma revisão. Ciência \& Saúde Coletiva, Rio de Janeiro, v.15, p. 3455-3466, 2010. Suplemento 3 .
MANDÚ, E. N. T. et al. Visita domiciliária sob o olhar de usuários do programa saúde da família. Texto \& Contexto Enfermagem, Florianópolis, v. 17, n. 1, p. 131-140, 2008.

MEIRELES, M. M. Anomia. Rio de Janeiro: Casa do Psicólogo, 2001.

MINAYO, M. C. S. O desafio do conhecimento: pesquisa qualitativa em saúde. São Paulo: Hucitec, 2000.

MISHIMA, S. M. et al. A assistência na Saúde da Família sob a perspectiva dos usuários. Revista Latino-Americana de Enfermagem, Ribeirão Preto, v. 18, n. 3, p. 148-156, 2010.

OLIVEIRA, E. M. Processos de apropriação da prática na construção do cuidado em saúde, sob a perspectiva de usuários do Programa de Saúde da Família Rural de Sacramento/MG. 2009. Dissertação (Mestrado em Ciências: Psicologia) - Faculdade de Filosofia, Ciências e Letras de Ribeirão Preto da Universidade de São Paulo, Ribeirão Preto, 2009.

OLIVEIRA, A. K. P.; BORGES, D. F. Programa de Saúde da Família: uma avaliação de efetividade com base na percepção de usuários. Revista de Administração Pública, Rio de Janeiro, v. 42, n. 2, p. 369-389, 2008.

PASCOE, G. C. Patient satisfaction in primary health care: a literature review and analysis. Evaluation and Program Planning, New York, v. 6, n. 3/4, p. $185-210,1983$.

PINHEIRO, R. Práticas de saúde e integralidade: as experiências inovadoras na incorporação e desenvolvimento de novas tecnologias assistenciais de atenção aos usuários no SUS. In: BRASIL. Ministério da Saúde. Secretaria de Gestão de Investimentos em Saúde. Projeto Reforsus Componente II. Experiências inovadoras no SUS: relatos de experiências: novas tecnologias assistenciais: Secretarias Estaduais e Municipais de Saúde. Brasília, DF, 2002. p. 15.

POPE, C.; MAYS, N. Pesquisa qualitativa na atenção à saúde. Porto Alegre: Artmed, 2005.

PRÉVOST, A. et al. La mesure de la satisfaction des usagers dans le domine de la santé et des services 
sociaux: l'experience de la Régie Régionale Chadière-Appalaches. The Canadian Journal of Program Evaluation, Toronto, v. 13, n. 1, p. 1-23, 1998.

ROZEMBERG, B.; MINAYO, M. C. S. A experiência complexa e os olhares reducionistas. Ciência \& Saúde Coletiva, Rio de Janeiro, v. 6, n. 1, p. 115-123, 2001.

SANTANA, H. S. Compreensão da prática médica sob a perspectiva de usuários do Programa de Saúde da Família Rural de Sacramento/MG. 2008. Dissertação (Mestrado em Saúde da Comunidade) - Faculdade de Medicina de Ribeirão Preto da Universidade de São Paulo, Ribeirão Preto, 2008.

SANTOS, S. M.; UCHIMURA, K. Y.; LANG, R. M. F. Percepção dos usuários do programa saúde da família: uma experiência local. Cadernos de Saúde Coletiva, Rio de Janeiro, v. 13, n. 3, p. 687-704, 2005.

SCOPINHO, R. A. Condições de vida e saúde do trabalhador em assentamento rural. Ciência \& Saúde Coletiva, Rio de Janeiro, v. 15, p. 1575-1584, 2010. Suplemento 1.

SERAPIONI, M.; SILVA, M. G. C. Avaliação da qualidade do programa Saúde da Família em municípios do Ceará: uma abordagem multidimensional. Ciência \& Saúde Coletiva, Rio de Janeiro, v. 16, n. 11, p. 4315-4326, 2011.

SILVA, N. C.; GARNELO, L.; GIOVANELLA, L. Extensão de cobertura ou reorganização da atenção básica?: a trajetória do Programa de Saúde da Família de Manaus-AM. Saúde e Sociedade, São Paulo, v. 19, n. 3, p. 592-604, 2010.
SOUSA, M. F.; HAMANN, E. M. Programa Saúde da Família no Brasil: uma agenda incompleta? Ciência \& Saúde Coletiva, Rio de Janeiro, v.14, p. 1325-1335, 2009. Suplemento 1.

SOUZA, E. C. F. et al. Acesso e acolhimento na atenção básica: uma análise da percepção dos usuários e profissionais de saúde. Cadernos de Saúde Pública, Rio de Janeiro, v. 24, p. 100-110, 2008. Suplemento 1.

TANAKA, O. Y. Avaliação da atenção básica em saúde: uma nova proposta. Saúde e Sociedade, São Paulo, v. 20, n. 4, p. 927-934, 2011.

TESSER, C. D. Social medicalization (II): biomedical limits and proposals for primary care clinics. Interface: Comunicação, Saúde, Educação, Botucatu, v. 10, n. 20, p. 347-362, 2006.

TRAD, L. A. B. et al. Estudo etnográfico da satisfação do usuário do Programa de Saúde da Família (PSF) na Bahia. Ciência \& Saúde Coletiva, Rio de Janeiro, v. 7, n. 3, p. 581-589, 2002.

UCHIMURA, K. Y.; BOSI, M. L. M. Qualidade e subjetividade na avaliação de programas e serviços em saúde. Cadernos de Saúde Pública, Rio de Janeiro, v. 18, n. 6, p. 1561-1569, 2002.

UCHOA, A. C. et al. Avaliação da satisfação do usuário do Programa de Saúde da Família na zona rural de dois pequenos municípios do Rio Grande do Norte. Physis, Rio de Janeiro, v. 21, n. 3, p. 10611076, 2011.

WARE J. E. et al. Defining and measuring patient satisfaction with medical care. Evaluation and Program Planning, New York, v. 6, n. 3/4, p. 247263, 1983.

\section{Contribuição dos autores}

Oliveira e Figueiredo trabalharam na concepção, coleta, análise, interpretação dos dados, revisão crítica e redação final do texto. Rocha e Magnabosco colaboraram na revisão crítica e redação final do manuscrito. Felipe e Santana trabalharam na coleta, interpretação dos dados e revisão crítica do texto.

Recebido: $20 / 03 / 2014$

Reapresentado: 25/06/2014

Aprovado:17/07/2014 